\title{
A Comparison of Transportation Systems for Human Missions to Mars
}

\author{
Brent Thomas", Diane Vaughan ${ }^{\dagger}$ \\ Gray-Research, Inc Huntsville, AL 35806 \\ Bret Drake ${ }^{\ddagger}$ \\ NASA Johnson Space Center, Houston, TX 77058 \\ Brand Griffin ${ }^{\S}$, Gordon Woodcock** \\ Gray-Research, Inc Huntsville, AL 35806
}

\begin{abstract}
There are many ways to send humans to Mars. Credible technical reports can be traced to the 1950's. More recently, NASA has funded major studies that depict a broad variety of trajectories, technologies, stay times, and costs. Much of this data is still valid with direct application to today's exploration planning. This paper presents results comparing these studies with particular emphasis on the in-space transportation aspects of the mission. Specifically, comparisons are made on propulsion systems used for getting the crew and mission equipment from Earth orbit to Mars orbit, descending and ascending from the surface, and returning to Earth orbit. Areas of comparison for each of these phases include crew size, mission mass, propellant mass, delta v, specific impulse, transit time, surface stay time, aero-braking, and others. Data is analyzed to demonstrate either strong trends toward particular technologies or diverging solutions.
\end{abstract}

\section{Purpose/Introduction}

Purpose

The purpose of this paper is to provide mission planners and analysts with a comparison of in space transportation characteristics found in key Mars studies.

Introduction

Today, many engineers are asked to conduct Mars analysis but have little understanding of the breadth and depth of previous work (see Fig. 1). One annotated bibliography refers to over 243 citations through December, 2000. Some studies are available through conventional literature searches; however, others are buried in filing cabinets at NASA Centers and in offices of Aerospace Contractors. The documentation is inconsistent and material comes in many different formats. Some are recorded as formal documents, others as interim study reports. Technical conference papers provide another source of published data, but the latest work is not in the public domain and only available in presentation chart form. Regardless, the work is impressive and because many of the issues are the same today, it represents an enormous resource for future Mars mission planning. Few engineers have ready access to these studies let alone the time to dig through 1000's of pages for a particular data point. This paper represents the process to identify key studies, collect the documentation and conduct comparison analyses, and present results as they apply to in-space transportation. While the comparisons are useful, it is important to note that because the underlying mission objectives, ground rules, and assumptions vary widely they do not represent a true apples-toapples comparison.

\footnotetext{
- Engineer, In-Space Propulsion, Gray Research, Huntsville, AL, non-Member

${ }^{\dagger}$ Systems Engineer, In-Space Propulsion, Gray Research, Huntsville, AL, non-Member

${ }^{\ddagger}$ Requirements Lead, Office of Exploration Systems/EX, NASA-JSC, Member

${ }^{\S}$ Manager, Systems Analysis and Space Architect, Gray Research, Huntsville, AL, Senior Member

"* Chief Technologist, Gray Research, Huntsville, AL, Senior Member
} 


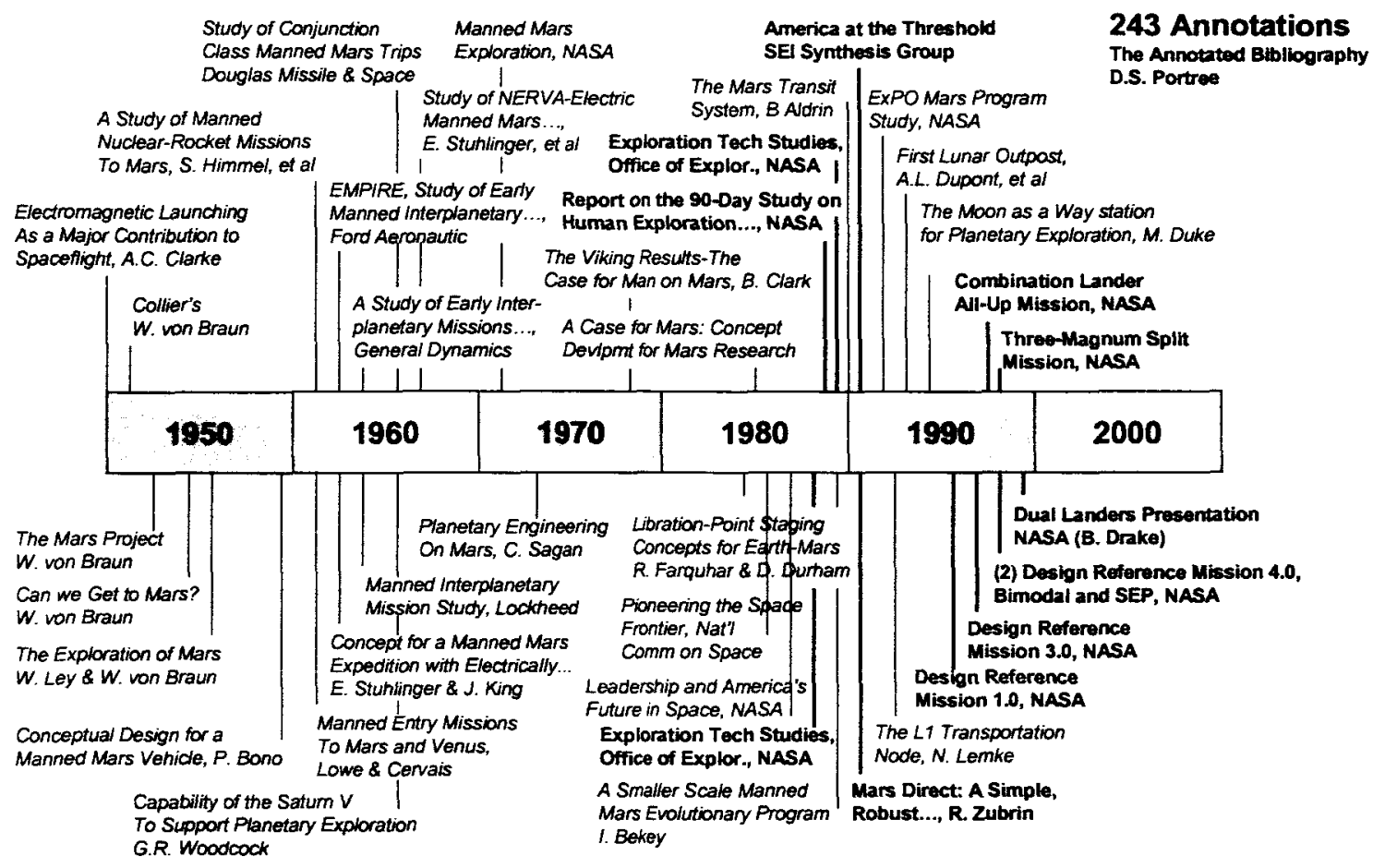

Figure 1 Timeline for Mars studies (Bold type represents selected studies)

\section{Approach}

\section{A. Survey of Studies, Reports and Technical Papers}

The process began with a comprehensive survey of studies, reports, and technical papers for human missions to Mars. Because there is no single repository of documentation on this subject, this process included research through NASA and contractor technical libraries, internet searches, and copying material from personal collections. A large volume of material was collected both in hard copy and electronic form. For this research, 21 studies were selected for comparison. Some are alternatives created within the same study, but because they represent a different approach, they were compared separately. The studies and rationale for selection are shown in Fig. 2. 


\begin{tabular}{|c|c|c|c|}
\hline Study & $\begin{array}{c}\text { Options within } \\
\text { Study }\end{array}$ & Acronym & Selection Rationale \\
\hline 1988/1989 Case Studies & 5 & $\begin{array}{l}\text { Exp-P, Exp-M, Evo88, } \\
\text { Evo89, Exp89 }\end{array}$ & $\begin{array}{l}\text { Agency-wide analysis of exploration options; provide focused program for human exploration of solar } \\
\text { system }\end{array}$ \\
\hline 90 Day Study & 1 & 90D & Large integrated NASA'Contractor effort, results well documented, includes design, schodule and cost \\
\hline $\begin{array}{l}\text { Synthesis Stady - America } \\
\text { at Threshold }\end{array}$ & 1 & Syn & $\begin{array}{l}\text { Chartered by National Space Council - "major study"; Explore Mars \& provide significant science } \\
\text { return }\end{array}$ \\
\hline Mars Direct & 2 & MDCh/MDNTR & $\begin{array}{l}\text { Low cost, no orbital rendervous or assembly, dependent upon ISRU propellant production for return; } \\
\text { Chemical and NTR options }\end{array}$ \\
\hline Mars Semi-Direct & 1 & MSD & Concept bridge between Zubrin Direct and Design Rreference Mission 1.0; low cost \\
\hline STCAEM Cryo/Aero & 1 & $\mathbf{S}-\mathbf{C} / \mathbf{A}$ & Major NASA funded study produced by Bocing in 1991; focus on in-space propulsion \\
\hline STCAEM NTR & 1 & S-NTR & Major NASA funded study produced by Boeing in 1991; focus on in-space propulsion \\
\hline STCAEM NEP & 1 & S-NEP & $\begin{array}{l}\text { Major NASA funded study produced by Boeing in 1991, only study chosen using Nuclear Electric } \\
\text { Propulsion as in-space propulsion }\end{array}$ \\
\hline STCAEM SEP & 1 & S-SEP & Major NASA funded study produced by Bocing in 1991; focus on in-space propulsion \\
\hline DRM 1.0 & $\mathbf{1}$ & DRM1 & $\begin{array}{l}\text { NASA's "Design Reference Mission" based upon previous studies; good focus on operations and } \\
\text { science return }\end{array}$ \\
\hline DRM 3.0 & 1 & DRM3 & $\begin{array}{l}\text { Refine DRM } 1.0 \text { systems concepts and design; smaller class lawnch veticle (80mt);source data from } \\
\text { Borowski paper }\end{array}$ \\
\hline DRM 4.0 & 2 & DRM4N/DRM4S & $\begin{array}{l}\text { Refine DRM 3.0; SEP Prop Option; NTR Bimodal "all-propulsive" option; source data from Borowski } \\
\text { NTR }\end{array}$ \\
\hline Combo Lander & 2 & CLACLS & $\begin{array}{l}\text { Focus on single Mars lander to transport crew \& also support on surface, all-up and split mission } \\
\text { scenarios }\end{array}$ \\
\hline Dual Lander & 1 & DUL & Follow-on of combo lander study - back to 2 landers, no formal report, presentation charts only \\
\hline
\end{tabular}

Figure 2 Rationale for individual study selection

\section{B. Rationale for Selecting Key Studies}

Mars studies are often complex with many interrelated variables. "An Overview of Recent Coordinated Human Exploration Studies" and "Key Findings from Previous NASA Exploration Mission Studies" are two NASA presentations that provide a good comparison of many of these variables. The analysis discussed in this paper builds upon this work while focusing on the attributes of in-space transportation.

One of the first considerations for selecting key studies was to determine the technological relevance. The first credible study was von Braun's "Das Marsprojekt" of 1952. NASA funded studies from about 1963 to about 1972. There was almost no study work from 1972 to 1988. All of the basic themes of Mars architectures (except perhaps solar electric propulsion) were pioneered in the old studies and repeated in the later studies. Studies that were published from 1988 to the present were chosen so that any modern technology development would be reflected in the comparisons. Also, 1988 was the year that President Bush formed the Mars Office of Exploration at NASA which resulted in plans for a number of reports on manned missions to Mars. These reports started a series of credible studies that would be produced over the following ten years.

Another guideline that was used in the selection of key studies was the quality and quantity of the documentation. There was a strong preference for published studies, in particular those resulting in formal documentation authored by NASA Headquarters. Published reports from NASA funded contractors were also considered an important source of information and, in some cases, a technical society paper was used because it best described the in-space transportation portion of a study. When no other documentation was available, presentations were accepted only because they represented the latest work.

Documents were screened for credible concepts that included enough information to be used in comparison. NASA and NASA funded aerospace contractors' studies were chosen because of the consensus nature of the work rather than a judgment on the feasibility of a particular concept.

Presidential support and new approaches to accomplish manned lunar and Mars missions were additional criteria for the selection of the key studies. Several studies were directly spawned from President George H. Bush's decree in July of 1989 to find new ways to go to the Moon and to Mars. Also, studies were selected based on the significant benefits produced from new approaches to get to Mars such as split missions (sending the equipment first then the crew) and Venus swing-by trajectories (using the gravity of Venus to reduce propulsion system mass).

It is important to note that cost was not a consideration for selecting or comparing key studies. Typically, any cost analysis was based on different assumptions, schedules, and risk. Although cost was not considered as a selection criterion, cost can often be equated to mass. Most costing models use mass as the primary driver for system cost, and thus mission designers typically strive to reduce overall and system masses. 


\section{Traceability of Data}

Due to the large number of studies collected and reviewed throughout this effort, the ability to locate pertinent study data and trace it back to its origin was an important objective in this research. A concerted effort was made to trace each piece of data back to a page and volume number within the study. Although time consuming, the benefit of this approach allowed revisits to the source material for future data collection. Millions, if not hundreds of millions, of dollars of analysis is represented in these reports and having a means of access to this data affords significant cost savings for future mission planners.

\section{Different Ground Rules and Assumptions}

It is difficult to compare one study to the next because each study had its own ground rules and assumptions. Some were motivated by scientific objectives and others by "flags and footprints". Some were constrained by schedule, cost, or technology readiness; others created very large launch vehicles, and others relied on making return propellant on the surface of Mars.

The common primary objective of each study was to safely send and return a crew to Mars. The secondary focus varied among the different studies reviewed. Some studies yielded more defined information in specific areas than others. Some of the specific areas included in-space propulsion and operations. In-space propulsion was better defined particularly in the Space Transfer Concepts and Analysis for Exploration Missions (STCAEM) reports which yielded four types of in-space propulsion applications using the same ground rules and assumptions. The Design Reference Mission 1.0 (DRM1) focused not only on landing a crew safely on the Martian surface but on providing them with the tools to accomplish science and exploration objectives. An "apples-to-apples" comparison between the studies is difficult due to the different ground rules and assumptions.

Technology advancement over current technology was assumed in all Mars related studies. Future technology development was expected and applied in the areas of propulsion and in-situ resource utilization to accomplish the overall complex Mars mission. Different studies took different approaches to the degree that they assumed technology development and readiness for the Mars mission in the launch opportunity investigated. Perhaps the greatest assumption in these studies was the large, yet-to-be-developed launch vehicle. This launch vehicle was used on the ground to place mission elements into Low Earth Orbit (LEO). Assumed launch vehicle lift capability ranged from $80 \mathrm{mt}$ to as large as $240 \mathrm{mt}$ across the board. The overall capacity of the launch vehicle affected the transportation system definition which drove the complexity of comparing the studies. It should be noted that the Saturn V vehicle had over a $100 \mathrm{mt}$. lift; therefore, an $80 \mathrm{mt}$. launch vehicle size is not radical.

\section{Mars Mission Planning}

\section{A. Trajectories}

The trajectories employed in each mission dictate different requirements for the mission ranging from launch opportunity dates to requirements for initial mass in low earth orbit (IMLEO). Trajectory options for the studies generally fall into two types of trajectory classes: opposition or "short-stay" and conjunction or "long-stay".

The first Mars mission class consists of short stay-times (typically 40 days) and round-trip mission times ranging from 365-660 days. This is often referred to as an opposition-class mission, although the exploration community has adopted the more descriptive terminology "short-stay" mission. Most opposition class missions try to use Venus Swing-by's as the nominal approach. A swing-by uses a planet's gravity to modify the trajectory to decrease the mission delta $v$ and reduce the trip time. Deep space maneuvers are used when Venus Swing-by's are not available for specific mission dates/trip times. Trajectory profiles for typical short-stay missions are shown in Fig. 3. This class of mission has high propulsive requirements even when employing a gravity-assisted swing-by of Venus or performing a deep space maneuver to reduce the total mission energy. Short-stay missions always have one short transit leg, either outbound or inbound, and one long transit leg, the latter requiring close passage by the sun (0.7 AU or less). After arrival at Mars, rather than waiting for a near-optimum return alignment, the spacecraft initiates the return after a brief stay and the return leg cuts well inside the orbit of the Earth to make up for the "negative" alignment of the planets that existed at Mars departure. Distinguishing characteristics of the short-stay mission are: 1) short-stay at Mars, 2) short to medium total mission duration, 3) perihelion passage inside the orbit of Venus on either the outbound or inbound legs, and 4) large total energy (propulsion) requirements. 

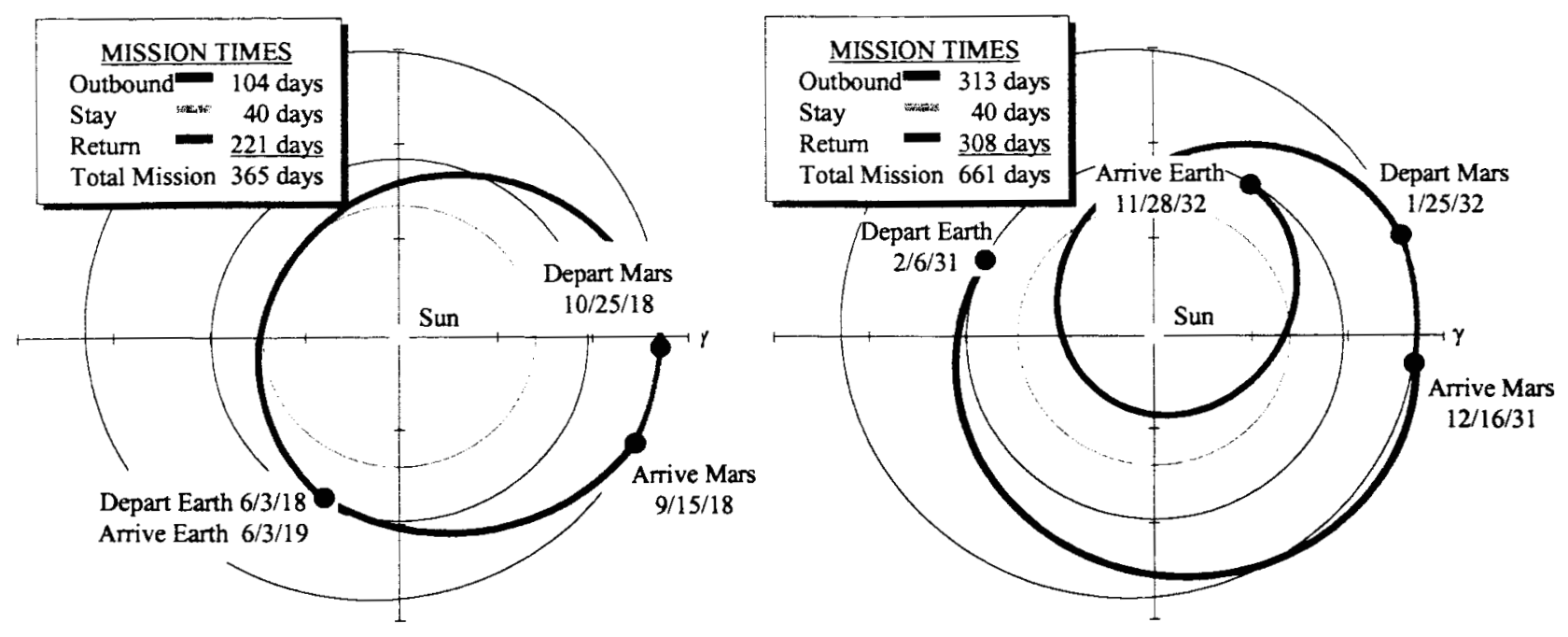

Figure 3 Short-stay (Opposition Class) mission profile examples

The short-stay mission approach has some distinct disadvantages. First, the total energy requirement, as measured in velocity change (delta- $v$ or $\Delta v$ ), varies greatly for each mission opportunity to Mars, repeating across the synodic cycle. (The synodic cycle is the period of time required for the relative phasing between Earth and Mars to repeat itself). The variation in total energy is also highly dependent on the total round-trip mission time and, in fact, can vary by as much as $\mathbf{8 8 \%}$ across the synodic cycle. For all Mars mission classes, as the trip time decreases, the required injection velocity and Mars arrival velocity both increase. This is important not only because higher total energies require exponentially greater propellant quantities, but also higher approach velocities can eliminate some leading technologies from consideration, such as aerocapture at Mars. In addition, the total round-trip mission times can be quite large up to 660 days, with only 40 days at Mars. These long periods in the deep-space environment raise many human health and performance issues that must be considered during the mission design process.

The second Mars mission class is typified by long-duration stay-times (as much as 600 days) and long total round-trip times (approximately 900 days). This mission type is often referred to as conjunction-class, although the exploration community has adopted the more descriptive terminology "long-stay" mission. These missions represent the global minimum-energy solutions for a given launch opportunity. Unlike the short-stay mission approach, instead of departing Mars on a non-optimal return trajectory, time is spent at Mars waiting for more optimal alignment for lower energy return. A variation of this long-stay mission type has recently gained attention. ${ }^{1}$ This mission has a total round-trip time comparable to those of the minimum-energy, long-stay missions, but the one-way transits are substantially reduced. Distinguishing characteristics of the long-stay mission include: 1) long total mission durations, 2) long-stays at Mars, 3) relatively little energy change between opportunities, 4) bounding of both transfer arcs by the orbits of Earth and Mars (closest perihelion passage of $1 \mathrm{AU}$ ), and 5) relatively short transits to and from Mars (less than 200 days). The mission flight profile for a typical fast-transit mission is shown in Fig. 4. 


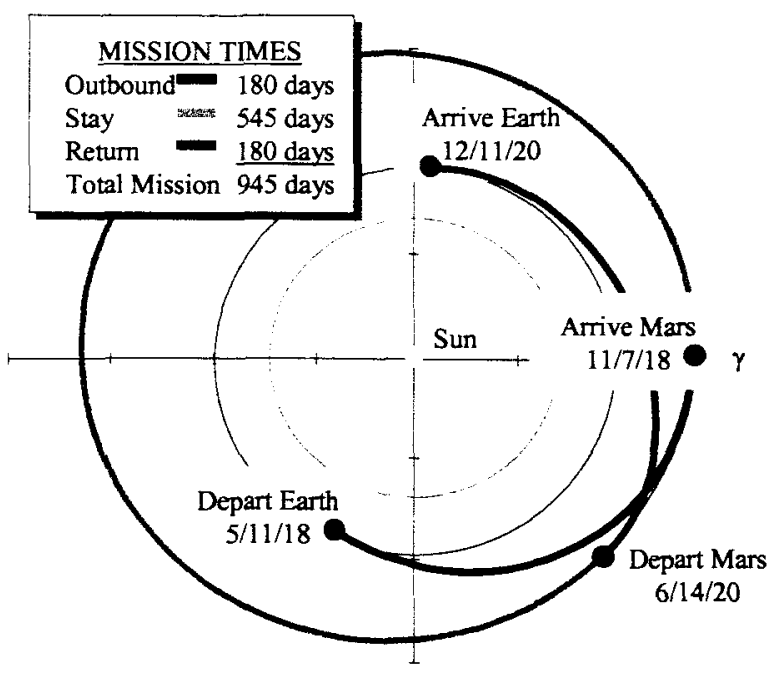

Figure 4 Trajectory profile for typical fast transit, long-stay (Conjunction Class) mission

\section{B. Propulsion Options}

Figure 5 describes different propulsion options encountered in this research. Advancement in the development of in-space propulsion systems will ultimately determine the extent of human endeavor in space. Propulsion is a primary cost driver for both the Mars spacecraft and their respective launch vehicles. Affordable space transportation will likely require implementation of advanced propulsion technologies. 


\begin{tabular}{|c|c|c|c|}
\hline Propulsion Option & Description & Advantages & Disedvantages \\
\hline Chemical Aerocapture & $\begin{array}{l}\text { Conventional cryogenic rocket engines, } \\
\text { usually one stage for each major } \\
\text { maneuver (TMI, MOI, TEI). Insulated } \\
\text { tanks with vapor-cooled shields to } \\
\text { reduce boiloff. Start T/W } 0.1 \text { to } 0.25 \text {. } \\
\text { Isp } 460 \text {. } \\
\text { Same as chemical except aerocapture } \\
\text { used for MOI. Large aeroshell needed } \\
\text { requiring either intact launch or in-space } \\
\text { assembly. Lander may capture } \\
\text { separately to simplify configuration. }\end{array}$ & $\begin{array}{l}\text {-Mature technology } \\
\text {-High thrust, short burn times } \\
\text {-Ballistic interplanetary transfers } \\
\text { facilitate implementing artificial gravity } \\
\text {-Reduces IMLEO by replacing one } \\
\text { major maneuver with aerocapture }\end{array}$ & $\begin{array}{l}\text {-Low performance leads to high IMLEO } \\
\text { except for conjunction profile with long } \\
\text { transfer times } \\
\text {-Cryogenic with hydrogen, low density, } \\
\text { needs heat leak control } \\
\text {-Expendable system } \\
\text {-Performance still marginal for "hard } \\
\text { year" opportunities } \\
\text {-Aerocapture risk: TPS/thermal, GN\&C } \\
\text {-Mars Vhp limited to } \sim 6 \text { for safe } \\
\text { aerocapture } \\
\text {-Expendable system }\end{array}$ \\
\hline NTR & $\begin{array}{l}\text { Nuclear thermal rocket engine, } \\
\text { hydrogen propellant, Isp } \sim 900 \text {. Usually } \\
\text { drop tanks utilized for each major } \\
\text { maneuver. Insulated tanks as above; } \\
\text { start } T / W<=0.1 \text { to reduce nuclear } \\
\text { engine size. }\end{array}$ & $\begin{array}{l}\text {-Known technology } \\
\text {-Twice the Isp of chemical propulsion } \\
\text { reduces IMLEO and sensitivity to } \\
\text { opportunity } \\
\text {-High thrust, short burn times } \\
\text {-Ballistic interplanetary transfers } \\
\text { facilitate implementing artificial gravity }\end{array}$ & $\begin{array}{l}\text {-Nuclear costs and risks } \\
\text {-Engine test protocols not resolved (how } \\
\text { to contain radioactive products) } \\
\text { - Cryogenic with hydrogen, low density, } \\
\text { needs heat leak control (exacerbated } \\
\text { because propellant is all hydrogen) } \\
\text {-Expendable system }\end{array}$ \\
\hline SEP & $\begin{array}{l}\text { Large (multi-megawatt) solar electric } \\
\text { propulsion system, performs all major } \\
\text { maneuvers. Isp typically } 3000 ; \text { MPD or } \\
\text { comparable thrusters. }\end{array}$ & $\begin{array}{l}\text {-Known technology with flight } \\
\text { experience in small size } \\
\text {-High Isp reduces IMLEO and } \\
\text { sensitivity } \\
\text {-No hydrogen propellant } \\
\text {-Reusable system }\end{array}$ & $\begin{array}{l}\text {-Large size may require more space } \\
\text { assembly than other options } \\
\text {-High-power electric thrusters not } \\
\text { mature (TRL } 2 \text { - 3) } \\
\text {-Achievable power-to-mass ratio may } \\
\text { not permit opposition-class profiles }\end{array}$ \\
\hline NEP & $\begin{array}{l}\text { Large (multi-megawatt) nuclear electric } \\
\text { propulsion system, probably Brayton or } \\
\text { liquid metal Rankine power generation, } \\
\text { performs all major maneuvers. Isp } \\
\text { typically } 3000 ; \text { MPD or comparable } \\
\text { thrusters. }\end{array}$ & $\begin{array}{l}\text {-Known technology (no space } \\
\text { experience or experimental prototypes } \\
\text { except thermoelectric and thermionic } \\
\text { conversion) } \\
\text {-High Isp reduces IMLEO and } \\
\text { sensitivity } \\
\text {-No hydrogen propellant } \\
\text {-Potentially reusable system }\end{array}$ & $\begin{array}{l}\text {-Nuclear costs and risks } \\
\text {-Large size may require more space } \\
\text { assembly than other options } \\
\text {-High-power electric thrusters and space } \\
\text { configuration power conversion not } \\
\text { mature (TRL 2 - 3) } \\
\text {-Achievable power-to-mass ratio may } \\
\text { not permit opposition-class profiles }\end{array}$ \\
\hline SEP/Chem & $\begin{array}{l}\text { Large SEP "tug" system 1 mega-watt } \\
\text { delivers chemical propulsion } \\
\text { interplanetary vehicle to highly elliptic } \\
\text { Earth orbit (perhaps in major sections } \\
\text { with berthing for assembly). Chemical } \\
\text { propulsion system departs from this } \\
\text { orbit; otherwise same as chemical } \\
\text { option. }\end{array}$ & $\begin{array}{l}\text {-Placement in elliptic orbit reduces } \\
\text { chemical delta V by } \sim 3 \mathrm{~km} / \mathrm{s} \text {, reducing } \\
\text { IMLEO and sensitivity to opportunity } \\
\text {-Other advantages same as Chemical } \\
\text { Option }\end{array}$ & $\begin{array}{l}\text {-Cost and mission complexity added by } \\
\text { use of SEP "tug" } \\
\text {-Cryogenic with hydrogen, low density, } \\
\text { needs heat leak control } \\
\text {-Expendable system }\end{array}$ \\
\hline
\end{tabular}

\section{Figure 5 Propulsion option advantages and disadvantages}

\section{Mission Approach}

Two approaches to mission design were researched: the all-up mission versus the split mission. The all-up mission requires both the cargo and the crew to leave Earth's orbit at the same time. In the split mission design, the cargo is flown to Mars prior to the crew's departure for Mars. The reason for the split is to send cargo and perhaps even return propellant on a low-energy trajectory which requires much less propellant.

Another feature of the transportation system is the method of orbit insertion. Studies have proposed both propulsive and aerocapture alternatives. The propulsive option uses the vehicle's propulsion system to reduce the delta $\mathrm{V}$ while aerocapture uses the planet's atmosphere to slow the vehicle down.

In-situ resource utilization (ISRU) is another option for a mission. ISRU is another way of saying "live off the land". ISRU can involve propellant production on the surface of Mars or one of its moons, using the resources of the Mars system for oxygen production, setting up a habitat on the surface where food can be grown and so on. The type 
of ISRU employed will determine what the mass requirement for the mission will be as well as other mission parameters.

Because of the physiological degradation during long periods of weightlessness, some human Mars missions incorporate all or part of the spacecraft rotation to produce artificial gravity. This, of course, has a significant impact on the design and location of propulsive elements. Although this should be considered a serious alternative, none of the key studies use the approach.

\section{AREAS OF COMPARISON AND RESULTS}

Common areas of comparison were identified so the differences across the Mars studies could be seen. Most areas related directly to the transportation system, but several areas such as crew size were included to provide context and indicator of mission scale.

An abundance of assembly data was collected and documented. In those missions requiring assembly, different Mars vehicle elements are launched into LEO on separate Heavy-Lift Launch Vehicle (HLLV) launches. Assembly may consist of a "simple" automated rendezvous and dock between elements or it can be much more complex requiring the use of the Space Station Freedom or an equivalent dedicated truss structure. Since the vehicle assembly process varied a great deal, a comparative analysis was not done.

Most studies described the type of propellant used for ascent and descent to and from the surface of Mars. Whether or not in-situ resource production propellant was assumed was also indicated. Since the focus of this paper was on in space transportation and some of the studies did not cover ascent/descent to the Mars surface, this was not an area that was compared except as it related to ISRU ascent propellant production.

For this research, a Mars mission is considered to be one round trip from Earth. This is important because some transportation schemes send the cargo ahead with the crew to follow. In this case, all crew and cargo launches required for a single round trip would be book-kept against the mission. Figure 6 shows a summary of the mission design options for the researched studies.

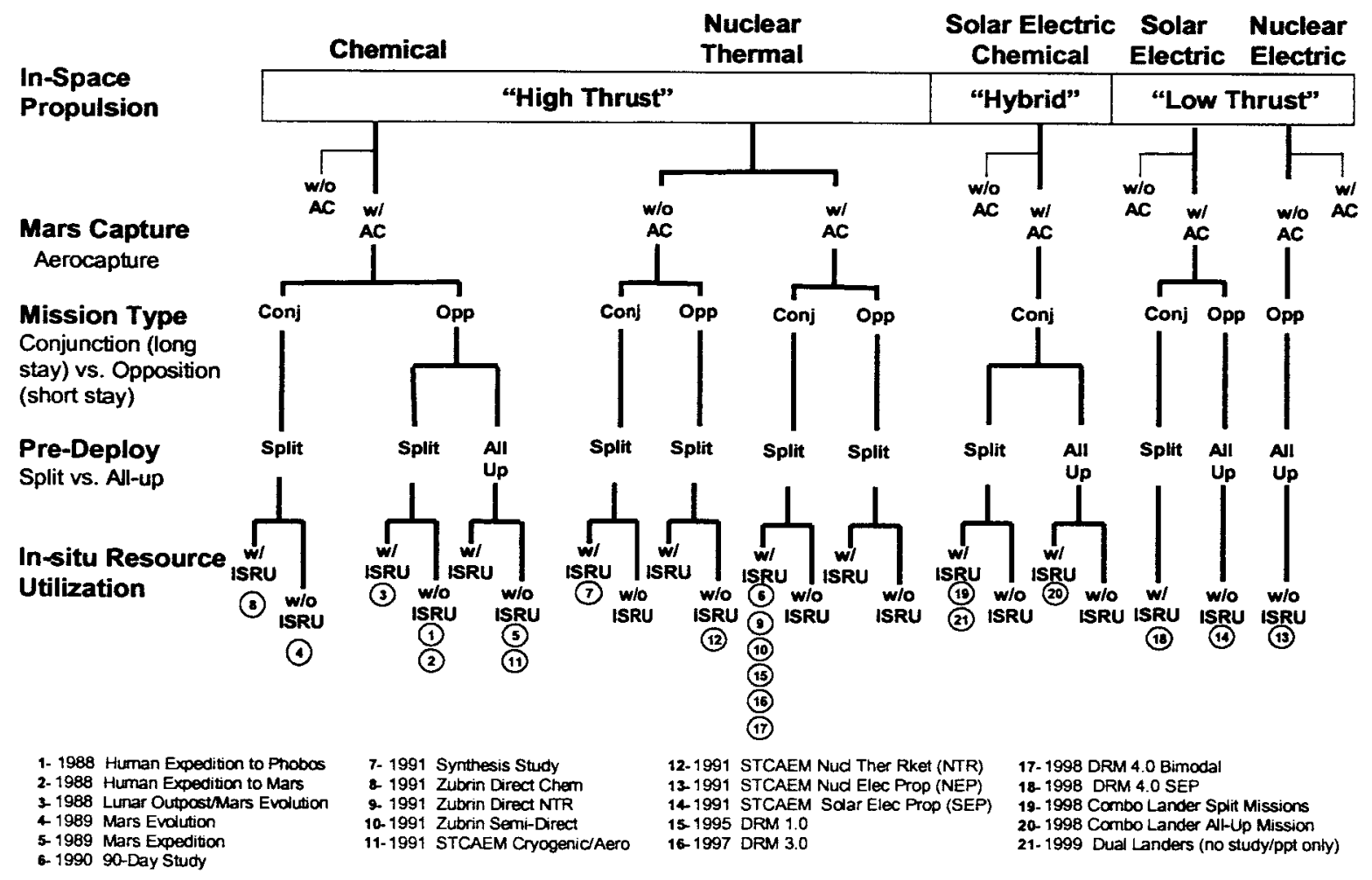

Figure 6 Mission design options for Mars studies 


\section{A. Earth Departure Date}

The Earth departure date, or launch window opportunity as it is sometimes referred to, would be the first date when a cargo and/or piloted vehicle would leave LEO. In an all-up mission approach, the piloted vehicle with relevant cargo would leave LEO and travel to Mars; thus, the mission will be accomplished during the designated opportunity window (i.e. CLA 2011). The alternative is the split sprint mission which requires two Earth departure dates or opportunities. The cargo would depart LEO on the first opportunity and the piloted vehicle would follow on the second opportunity (i.e. DRM1 2009/2011).

As mentioned earlier, Mars mission planning is typically done on a 15 year synodic cycle. Within this synodic cycle period, some launch dates will be "easier" than others due to trajectory differences that occur during sequential mission opportunities. This difference has a tremendous impact on the design of a transportation system. Some of the studies documented (i.e. DRM1) took a conservative approach of designing to the hardest opportunity year (2009) in the synodic cycle. The philosophy behind this rationale is that excess system capability may be available in the easier departure dates such that additional payload mass in the form of cargo or crew members may be afforded.

Of the 21 studies surveyed, launch window opportunities ranged from 1997 to 2018 as the start date for a Mars vehicle to leave LEO. The earliest launch is Mars direct in 1997. The latest initial launch refers to the 90-Day Study in 2018. Figure 7 shows the first crew departure date from LEO. Some studies may have addressed several departure dates across the entire synodic cycle as part of a process of building a self-sufficient Mars outpost.

\begin{tabular}{|c|c|c|c|}
\hline Acronym & Stady Titie & Acromye & Stady Tite \\
\hline Exp-P & (1988) Expedition to Phobos & S-NTR & (1991) STCAEM NTR \\
\hline Exp-M & (1988) Expedition to Mars & S-NEP & (1991) STCAEM NEP \\
\hline Evo88 & (1988) Mars Evolution & S-SEP & (1991) STCAEM SEP \\
\hline Evo89 & (1989) Mars Evolution & DRM1 & (1995) Design Ref Msn 1.0 \\
\hline Exp89 & (1989) Mars Expedition & DRM3 & (1997) Design Ref Msn 3.0 \\
\hline $90 \mathrm{D}$ & $(1990) 90$ Day & DRM4N & (1998) DRM 4.0 Bimodal \\
\hline Syn & (1991) Synthesis & DRM4S & (1998) DRM 4.0 SEP \\
\hline $\mathrm{MDCh}$ & (1991) Mars Direct Chem & CLA & (1998) Combo Lander All-Up \\
\hline MDNTR & (1991) Mars Direct NTR & $\mathrm{CLS}$ & (1998) Combo Lander Split \\
\hline MSD & (1991) Mars Semi-Direct & DUL & (1999) Dual Landers \\
\hline $\mathrm{S}-\mathrm{C} / \mathrm{A}$ & (1991) STCAEM Cryo/Aero & & \\
\hline
\end{tabular}

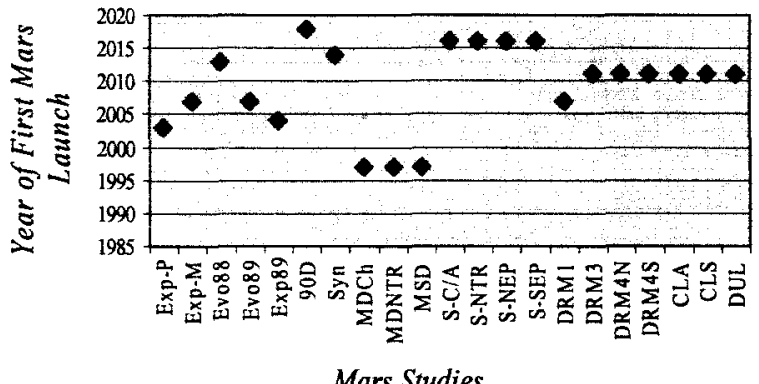

Figure 7 Study legend and Earth departure dates for chosen Mars studies

\section{B. Crew Size}

When humans are factored into the Mars mission equation, the Mars mission becomes increasingly complex. Increased system reliability along with adequate consumables and travel accommodations will drive the mission design and transportation system. After departure from LEO, the crew is committed to the Mars journey without resupply from Earth. As a result, trade-offs are usually made between cost and comfort as well as performance and risk. Almost no studies have investigated the relationship between crew size and crew safety. STCAEM did perform one analysis and concluded seven or eight was the minimum crew size to have an adequate skill/training mix with allowance for one disabled crew person.

Defining a crew size for a Mars mission is a very significant parameter in determining systems design. Crew size affects the scale of the habitat and the space transportation system as well as others systems that directly support the crew. Therefore, the crew size is directly related to mission cost.

Many of the studies concentrated on an optimal skill mix for choosing crew members while others were concerned with the overall mission cost. Requirements for the crew size and composition of the crew would require considerable effort for future studies. Operational tasks would need to be well-defined along with safety and risk considerations. Crew dynamics would also be an important consideration. Figure 8 shows the variance in crew size from as few as three crew members for the initial mission to as many as eight crew members. 


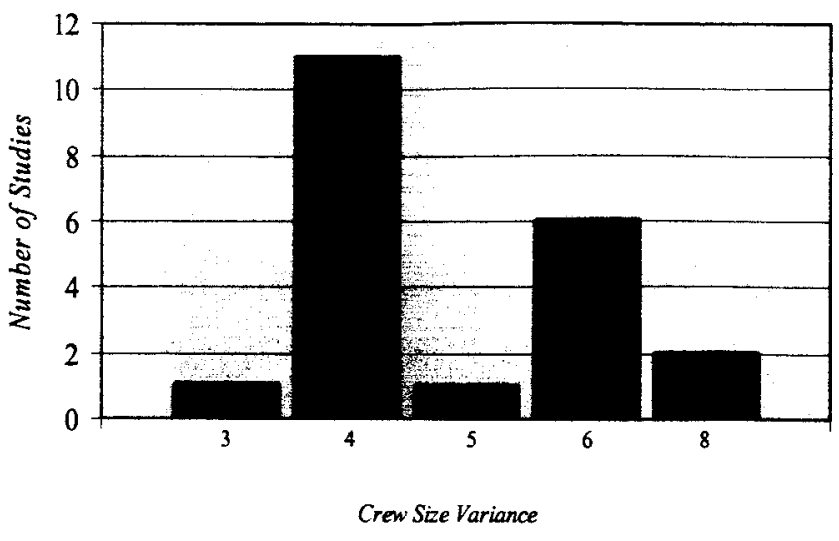

\begin{tabular}{|l|c|l|c|}
\hline Study & Crew Size & Study & Crew Size \\
\hline Exp-P & 4 & S-NTR & 4 \\
\hline Exp-M & 8 & S-NEP & 4 \\
\hline Ev088 & 8 & S-SEP & 4 \\
\hline Ev089 & 5 & DRM1 & 6 \\
\hline Exp89 & 3 & DRM3 & 6 \\
\hline 90D & 4 & DRM4N & 6 \\
\hline Syn & 6 & DRM4S & 6 \\
\hline MDCh & 4 & CLA & 4 \\
\hline MDNTR & 4 & CLS & 4 \\
\hline MSD & 4 & DUL & 6 \\
\hline S-C/A & 4 & & \\
\hline
\end{tabular}

Figure 8 Crew size variance for chosen Mars studies

\section{Cargo Mass to Surface}

Payload cargo mass is the amount of cargo delivered to the surface of Mars by the transportation system on a single injection opportunity from Earth. This cargo may consist of consumables such as crew supplies and food, power systems, and possibly a surface habitat. Upon completion of a mission, this cargo remains on the planet surface as a building block for a Mars outpost.

One way to measure the overall effectiveness of a Mars mission was to look at the amount of cargo or payload that reached the surface of the planet. Naturally, one of the goals for each mission would be to deliver as much cargo as possible for the least amount of cost. Since cost was not an area of comparison due to lack of data and consistency, the amount of cargo delivered to the surface was the area addressed in Figure 9 without regard to cost. No data was found for the Synthesis Study. Mars Evolution (1988) delivered the greatest amount of cargo while Mars Expedition (1989) delivered the least.

The requirement for cargo delivery varied greatly within the studies. Many studies may have underestimated it to reduce the cost estimate. Cargo delivered is useful information, but may not be realistic.

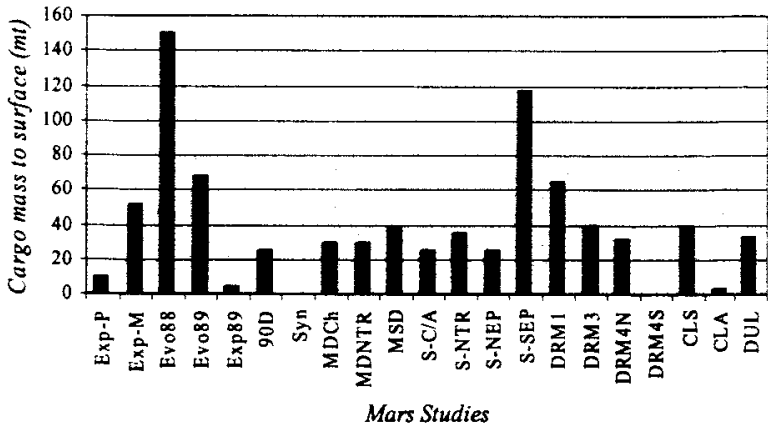

*No data found for Synthesis Study \& DRM4S Figure 9 Cargo mass payload to Mars surface

split sprint mission approach.

On one hand, the all-up mission design would be less risky for the crew in that they would not be separated from their cargo. On the other hand, in a split sprint mission design, the crew would be new to a landing site not having the benefit of a previously landed cargo mission. However, splint sprint missions generally provide for redundant consumables and/or abort options in the event that the piloted mission is unable to rendezvous with their cargo on the Mars surface at the designated landing site.

\section{Split/All-Up Mission Approach}

A split sprint mission sends cargo ahead of the manned flight. It consists of one or more cargo launches and ends with a piloted launch. These launches occur over sequential mission launch opportunities (i.e. 2009/2011). In contrast, the all-up mission approach includes both cargo and crew in the same flight opportunity.

Of the 21 studies researched, 5 used an all-up mission approach where cargo and crew arrive at the Red Planet at the same time. However, a conjunction mission may preposition cargo on Mars' surface as was the case in many of the researched studies. It appears that the trend of Mars mission design leans toward the 


\section{E. Trip Time/Trajectory}

All Mars mission designs have associated trip times. A trip time is the time it takes for a flight, either cargo or manned, to complete a mission. The travel to Mars is referred to as the outbound leg of the journey. Conversely, the return trip to Earth is called the inbound leg of the journey. Nested in between the outbound and inbound legs is the Mars surface stay time in which the crew performs exploration and science. Trip time is generally referred to as outbound, stay time, and inbound legs.

The two basic trajectory options are conjunction or opposition trajectories. Each option is generally characterized by the amount of time required to complete a mission: outbound to Mars, surface stay time, and inbound to Earth. Opposition missions are sometimes referred to as short-stay missions, 30-100 days spent on the Martian surface. Conjunction missions or long-stay missions generally spend 500-1000 days on the surface of the Red Planet.

Most opposition class missions try to use Venus Swing-by's; deep space maneuvers are used when Venus Swing-by's are not available for specific mission dates and associated trip times. The STCAEM Nuclear Electric Propulsion (NEP) opposition trajectory includes a lunar swing-by leg.

Mission outbound times were 80 days (Mars Direct) to 335 days (STCAEM Cryo/Aero). In general, the inbound times were the same or somewhat quicker. Of the studies surveyed, the 90-Day Study had the longest duration stay of 600 days. Figure 10 shows the trajectory options chosen and mission trip times for the chosen studies.

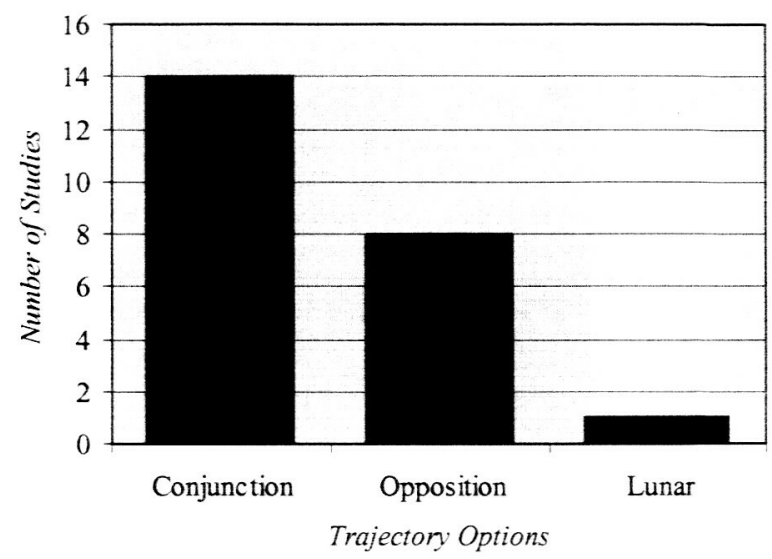

\begin{tabular}{|l|l|l|}
\hline Conjunction & Opposition & Lunar Swingby \\
\hline Evo88-in & Exp-P & S-NEP \\
\hline Evo89 & Exp-M & \\
\hline 90D & Evo88-out & \\
\hline Syn & Exp89 & \\
\hline MDCh & S-C/A & \\
\hline MDNTR & S-NTR & \\
\hline MSD & S-NEP & \\
\hline DRM1 & S-SEP & \\
\hline DRM3 & & \\
\hline DRM4N & & \\
\hline DRM4S & & \\
\hline CLA & & \\
\hline CLS & & \\
\hline DUL & & \\
\hline
\end{tabular}

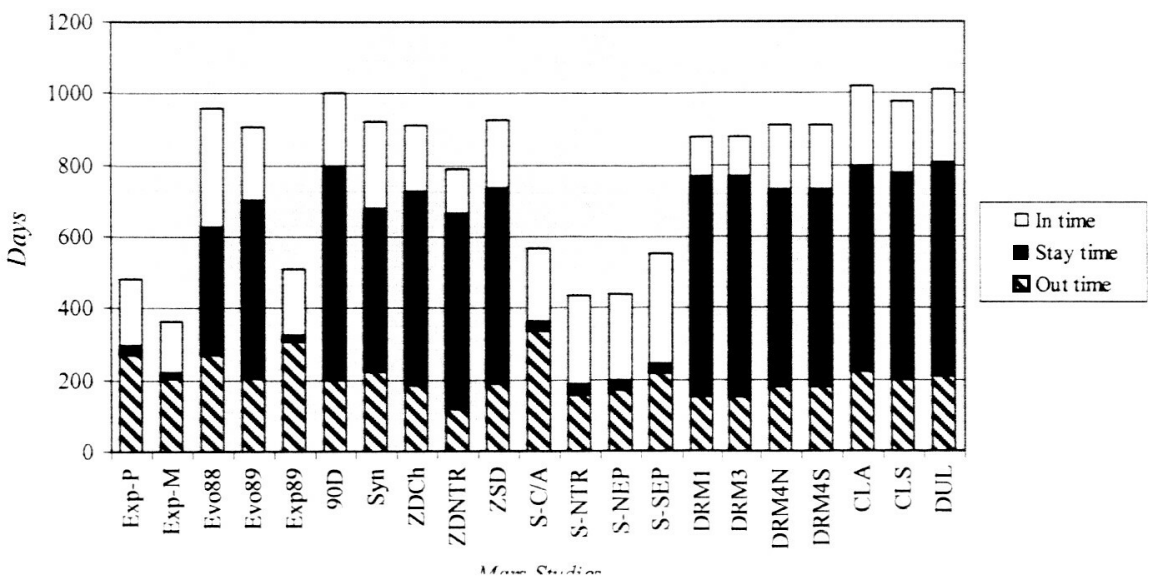

Figure 10 Trajectory selections and Mars mission trip time comparison

F. In-Situ

In-situ

Resource

resource utilization (ISRU) is the process of mining and using existing resources on Mars to produce primarily ascent propellant and perhaps surface rover fuel. Since propellant mass is a large portion of overall mission mass, ISRU would contribute greatly to the feasibility of a Mars mission at a reduced cost. Many of the studies made the assumption that ISRU would be a developed and available technology when the mission took place. ISRU technology development would not only produce ascent propellant but would also support crew activities and reduce risk. 
In-situ resource utilization requires future technology development in order to rely on resource processing and mining from Mars. It was viewed as an integral factor for a successful mission in many of the studies. A clear twothirds of the studies incorporated in-situ resource utilization as part of their mission design.

Many of the studies viewed in-situ resource utilization as a technology requirement that would, at a minimum, produce propellant using seed-hydrogen from Earth. The hydrogen would catalytically react with Martian $\mathrm{CO}_{2}$ to produce methane and water eliminating the need to store cryogenic hydrogen in the Martian surface. The methane and water would be stored and liquefied then chemically reacted to produce a methane/oxygen bipropellant. ${ }^{7}$ This bipropellant would be used to refuel a Mars ascent vehicle upon departure.

The Mars Direct Study is $100 \%$ dependent upon ISRU propellant production. Some of the other studies view ISRU as a technology development that would be a critical component especially for a long-term Mars outpost establishment. In-situ resource utilization can be characterized as "living off of the land". Its greatest potential would be to provide self-sufficiency in terms of providing greater resources for a broader range of transportation, habitation, life sciences, construction, energy production and other long term activities. ${ }^{5}$

\section{G. Propulsion Type}

There are many ways to design a Mars mission. The types of propulsion used for the studies surveyed were Chemical, Nuclear Thermal Rocket, Nuclear Thermal Electric, Solar Electric or a hybrid of Solar Electric and Chemical using an aerobrake referred to as SEP/Chem/Aerobrake.

Figure 11 shows the 5 different propellant types considered in the 21 studies documented. Almost an even split occurs between Chemical propulsion ( 7 studies) and Nuclear Thermal Rocket propulsion ( 8 studies). The remaining 6 studies used Solar Electric Propulsion or SEP with a chemical stage for Trans-Mars Injection (TMI) with only one study using Nuclear Electric Propulsion.

Choice of propellant greatly drives the Mars mission design. As an example, trade-offs were made in the area of radiation danger to the crew. The danger of nuclear radiation from an NTR or NEP was traded with the benefits of a fast-transit trajectory that would decrease the danger of crew exposure to in-space radiation caused by solar particle events and galactic cosmic radiation. On the other hand, use of chemical propulsion does not produce nuclear radiation to the crew but generally yields longer trip times thus greater crew exposure to in-space radiation. NTR advocates would argue that total crew exposure is less with NTR because of the shorter trip times possible. Section III- $B$ presents advantages and disadvantages for using different types of propulsion.

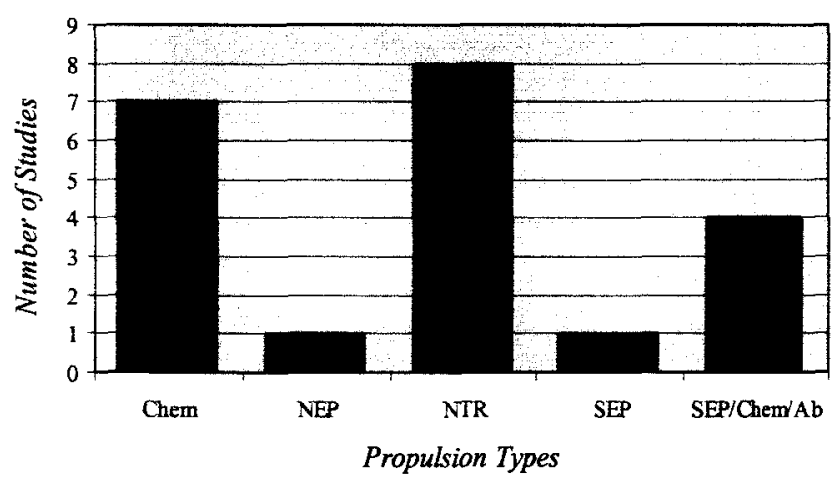

\begin{tabular}{|l|l|l|l|l|}
\hline \multicolumn{1}{|c|}{ Chem } & NEP & NTR & SEP & SEP/Chem/Ab \\
\hline Exp-P & S-NEP & 90 D & S-SEP & DRM4S \\
\hline Exp-M & & Syn & & CLA \\
\hline Ev088 & & MDNTR & & CLS \\
\hline Ev089 & & MSD & & DUL \\
\hline Exp89 & & S-NTR & & \\
\hline S-C/A & & DRM1 & & \\
\hline MDCh & & DRM3 & & \\
\hline & & DRM4N & & \\
\hline
\end{tabular}

Figure 11 Mars study propulsion selection

\section{H. Propellant Load}

The propellant load is the amount of propellant required to perform a complete mission (includes cargo flights and one manned flight). Propellant is the largest item contributing to the overall mission mass in Low Earth Orbit . Any reduction in the propellant mass would reduce the overall cost of a mission in terms of smaller launch vehicle size/lift capability and reduced number of launches from the ground.

Figure 12 shows the amount of propellant required for each Mars mission and the corresponding overall mission mass, measured IMLEO. The propellant load is a significant contributor to IMLEO. Propellant mass numbers were not found for Mars Direct NTR, Lunar Outposts/Mars Evolution (1988), or the Combination Lander All-up studies.

Although cost was not an area of comparison in this research due to lack of data and consistency, the greater the initial mass in low Earth orbit (IMLEO), the greater the cost to perform the mission. IMLEO numbers are compared across the studies in Fig. 16 below. The Human Expedition to Phobos published in 1988 yielded the greatest IMLEO as compared to the other studies. The Mars Direct scenarios came in at the lowest IMLEO essentially 7.4 times less 
than the Human Expedition to Phobos. It should be noted that the main goal of the Mars Direct scenario was low cost hence low IMLEO. It should be observed that the degree of design optimism varies widely among the studies and one should be cautious about drawing too many conclusions from IMLEO comparisons.

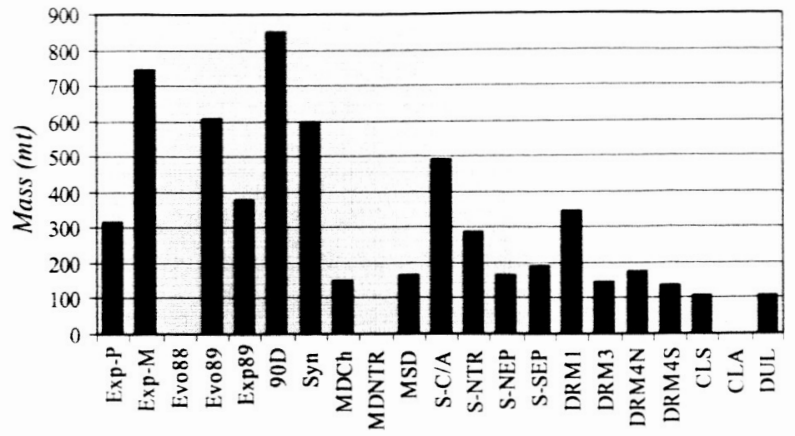

Study Propellant Load

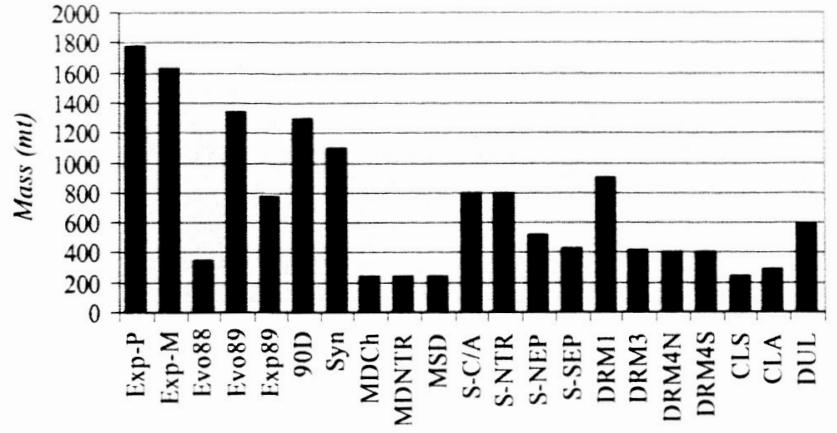

Mars Studies

* Propellant Load numbers for MDNTR, CLA, and Evo88 not found.

Figure 12 Propellant Mass and IMLEO for One Mars Mission

\section{Aeroassist at Mars/Descent to Mars Surface}

Aerocapture or aeroassist is a form of aerobraking. When most of these studies were done, aerocapture and aerobraking were used interchangeably. Since then, aerobraking has come to mean the slow process of gradually circularizing a parking orbit by repeated skims of the upper atmosphere, e.g. of Mars. Now one should use aerocapture to describe the process of capturing into an orbit on a single pass. The aerocapture process decreases vehicle speed by using the Mars atmospheric drag to slow the vehicle while deploying a braking device to reach an intended orbit.

Some studies used an aerobrake for capture into Mars orbit and for the Mars descent maneuver. Others used the descent lander Reaction Control System (RCS) propulsion and parachutes. Still other studies used a combination of the aforementioned upon descent to the Red Planet.

Figure 6, "Mars Capture" shows the use of aeroassist across the missions studied. Of the 21 studies, 5 used an allpropulsive capture into Mars orbit while 16 employed the use of aeroassist.

\section{J. Heavy Lift Launch Capability /Number of Launches per Mission}

Each study surveyed employed the use of a HLLV to place a Mars mission element from the ground into Low Earth Orbit (LEO). These vehicles were largely undefined and considered to be an area of new technology development. The amount of cargo/crew/payload is confined to the lift capability of each vehicle.

The capacity of the launch vehicle drives the number of launches. The DRM1 mission had an enormous launch vehicle size of $240 \mathrm{mt}$ but only three launches to avoid in-space assembly. Each element was directly launched into LEO and following system checkout proceeded with the outbound leg of the journey to Mars. Other studies chose smaller, assumed HLLVs (still requiring technology development) and more complicated in-space assembly (i.e. STCAEM NEP). Results comparing the size of the HLLV and the number of launches/mission are presented in Fig. 13.
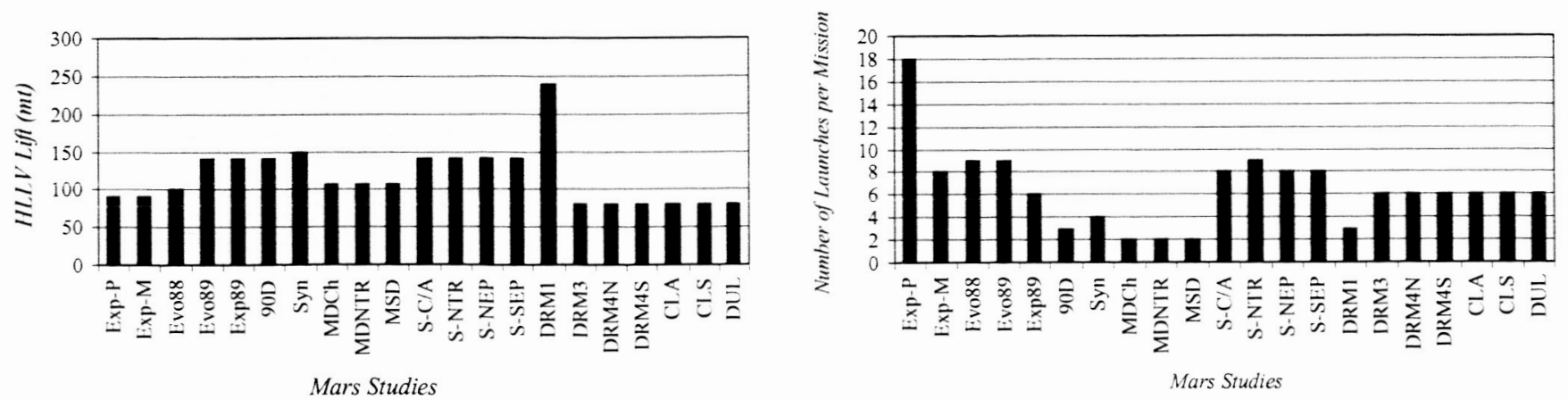

Figure 13 Assumed Mars launch vehicle capability and number of launches for one Mars mission 


\title{
V. Supporting Data
}

\author{
Supporting Personnel \\ Mary Ellen Harris SAIC Library (Archives) \\ Ben Donahue Boeing (Mars Studies + Archives) \\ Vance Houston NASA MSFC Archives
}

\author{
Acronyms and Abbreviations \\ 90D 1989 Report of the 90-Day Study on Human Exploration of the Moon and Mars \\ CLA Combination Lander All-Up \\ CLS Combination Lander Split \\ delta v delta velocity; change in velocity \\ DRM Design Reference Mission \\ DRM1 Design Reference Mission version 1.0 \\ DRM3 Design Reference Mission version 3.0 \\ DRM4N Design Reference Mission version 4.0-NTR Bimodal "all propulsive option" \\ DRM4S Design Reference Mission version 4.0 - SEP option \\ DUL Dual Landers Presentation \\ ETO Earth To Orbit \\ Evo88 1988 Exploration Studies Technical Report: Lunar Outpost to Early Mars Evolution \\ (Case Study 4) \\ Evo89 1989 Exploration Studies Technical Report: Mars Evolution Case Study \\ Exp89 1989 Exploration Studies Technical Report: Mars Expedition Case Study \\ Exp-M 1988 Exploration Studies Technical Report: Human Expedition to Mars (Case Study 2) \\ Exp-P 1988 Exploration Studies Technical Report: Human Expedition to Phobos (Case Study 1) \\ HEO High Earth Orbit \\ HLLV Heavy-Lift Launch Vehicle \\ MMLEO Initial Mass in Low Earth Orbit \\ ISRU In-situ Resource Utilization \\ LEO Low Earth Orbit \\ L2 Libration Point 2 \\ MDCh Mars Direct Study: Chemical Propulsion option \\ MDNTR Mars Direct Study: Nuclear Thermal option \\ MSD Mars Semi Direct Study \\ NEP Nuclear Electric Propulsion \\ NTR Nuclear Thermal Rocket \\ RCS Reaction Control System \\ S-C/A 1991 Space Transfer Concepts and Analysis for Exploration Missions, \\ Volume 2: Cryo/Aerobrake Vehicle \\ SEP Solar Electric Propulsion \\ S-NEP 1991 Space Transfer Concepts and Analysis for Exploration Missions, \\ Volume 5: Nuclear Electric Propulsion Vehicle \\ S-NTR 1991 Space Transfer Concepts and Analysis for Exploration Missions, \\ Volume 3: Nuclear Thermal Rocket Vehicle \\ S-SEP 1991 Space Transfer Concepts and Analysis for Exploration Missions, \\ Volume 4: Solar Electric Propulsion Vehicle \\ STCAEM Space Transfer Concepts and Analysis for Exploration Missions \\ Syn 1991 Synthesis Group Study - "America at the Threshold" \\ TMI Trans-Mars Injection \\ References \\ ${ }^{1}$ Soldner, J.K., "Round-Trip Mars trajectories - New Variations on Classic Mission Profiles," AIAA Paper No. \\ 90-2932, AlAA/AAS Astrodynamics Conference, Portland, OR, August 20-22, 1990. \\ ${ }^{2}$ NASA. "Exploration Studies Technical Report." NASA-TM-4075, 1988. \\ ${ }^{3}$ NASA. "Exploration Studies Technical Report." NASA-TM-4170, 1989.
}


"NASA. "Report of the 90 Day Study on Human Exploration of the Moon and Mars."

NASA internal report. 1989.

SNASA. "America at the threshold: America's Space Exploration Initiative." Report of the Synthesis Group. 1991.

6"Space Transfer Concepts and Analysis for Exploration Missions," The Boeing Co., Volumes 2 - 5, NAS837857, Huntsville, AL, March 1991.

${ }^{7}$ Reference Mission Version 3.0 Addendum to the Human Exploration of Mars: The reference Mission of the NASA Mars Exploration Study Team, edited by B. G. Drake, Exploration Office document EX13-98-036, June 1998.

${ }^{8}$ Zubrin, R., and Weaver, D., "Practical Methods for Near-Term Piloted Mars Missions", AIAA 93-2089, presented at 29th Joint Propulsion Conference and Exhibit, Monterey, Calif., June 28-30, 1993.

'Larson, Wiley J., and Pranke, Linda K., Human Spaceflight: Mission Analysis and Design, $2^{\text {nd }}$ ed., Mcgraw-Hill, New York, 2000.

${ }^{10}$ Borowski, Stanley K., Dudzinski, Leonard A., and McGuire, Melissa L., "Vehicle and Mission Design Options for the Human Exploration of Mars/Phobos Using "Bimodal" NTR and LANTR Propulsion," NASA TM-1998208834, 1998. 